\title{
OBJETO TÉCNICO, MEDIAÇÃO E ENSINO REFLETIDO DA TÉCNICA EM SIMONDON $^{1}$
}

\author{
José Fernandes Weber
}

RESUMO: O objetivo do artigo é apresentar como Simondon concebe o objeto técnico, a mediação e o ensino refletido da técnica. Num primeiro momento será apresentada a defesa dos objetos técnicos frente a acusação de restrição da experiência humana, da cultura. Num segundo, será apresentada a genealogia do objeto técnico, compreendido enquanto mediação entre o homem e a natureza, para então abordar o tema do ensino refletido da técnica.

PALAVRAS-CHAVE: Objeto técnico; Cultura; Mediação; Ensino; Simondon.

RESUMEN: El objetivo del artículo es presentar la manera como Simondon concibe el objeto técnico y la enseñanza reflectida de la técnica. En primer momento se presentará la defensa de los objetos técnicos frente a la acusación de restricción de la experiencia humana, de la cultura. A continuación, se presentará la genealogía del objeto técnico, conprendido como mediación entre el hombre y la naturaleza, para entonces tratar del tema de la enseñanza reflectida de la técnica.

PALABRAS CLAVE: Objeto técnico; Cultura; Mediación; Enseñanza; Simondon.

O homem já não tem necessidade de uma liberação individualizante, e sim, de uma mediação (Simondon, 2007, p. 122).

A vigência da tecnologia tornou-se imperativa na contemporaneidade. Por isso, é impossível imaginar, dado o profundo e vertiginoso nível do desenvolvimento tecnológico, práticas ou concepções que abdicassem

\footnotetext{
${ }^{1}$ Trabalho resultante das atividades desenvolvidas no projeto de Pesquisa "Técnica, tecnologia em Heidegger e Simondon: destruição do pensamento ou ampliação da experiência?" PROPPG/UEL, financiado pelos seguintes órgãos de fomento: 1. MCTI/CNPq/CAPES (Chamada 07/2011); 2. Fundação Araucária (Chamada 05/2011); 3. FAEPE/UEL (Edital 01/2011); 4. Fundação Araucária (Bolsa Produtividade em Pesquisa); 5. Bolsa de Pós Doutorado (Fundação Araucária/CAPES - CP 12/2013 ).

" Professor do Departamento de Filosofia da Universidade Estadual de Londrina (UEL). Email: jweber@uel.br

WEBER, José Fernandes. Objeto técnico, mediação e ensino refletido da técnica em Simondon. Revista Sul-Americana de Filosofia e Educação. Número 20: maio-out/2013, p. 136-156.
} 
radicalmente das conquistas tecnológicas. Tanto é que, sobre os que insistem em não render-se à tecnologia, paira uma suspeita de arcaísmo, pois não apenas a dimensão material do mundo - os objetos -, mas também as "configurações subjetivas" - o imaginário, a representação de si, dos outros e do mundo, por exemplo - são marcadas e constituídas indelevelmente pelo modo tecnológico de criar e representar o mundo e o humano. Disso resulta uma cada vez maior consciência da importância da tecnologia, pois sua vigência não opera apenas uma transformação do mundo circundante externo - ela não apenas cria objetos com os quais se modifica a paisagem externa -, mas também opera uma transformação do próprio humano. Se ela opera uma forma ampla de subjetivação, abdicar de considerá-la em toda sua extensão, significaria restringir consideravelmente a própria apreensão do humano em suas possibilidades. Pierre Lévy (2010, p. 07), no parágrafo de abertura de As tecnologias da inteligência, diz:

Novas maneiras de pensar e de conviver estão sendo elaboradas no mundo das telecomunicações e da informática. As relações entre os homens, o trabalho, a própria inteligência dependem, na verdade, da metamorfose incessante de dispositivos informacionais de todos os tipos. ${ }^{2}$

Por tal razão, fácil será constatar que a tecnologia, enquanto tema privilegiado para a reflexão sobre o modo contemporâneo de ser, não se limita ao âmbito de abrangência dos objetos tecnológicos que tornam nossa vida mais cômoda. Se este plano, o da presença dos objetos tecnológicos no nosso quotidiano, é o mais visível, com o qual mantemos maior proximidade, dada justamente pelas facilitações que ele proporciona, contudo, a tecnologia abrange outras dimensões nas quais nossa tranquilidade é desestabilizada. Refiro-me, por exemplo, à possibilidade de, em decorrência do desenvolvimento tecnológico, ao mapear o código genético, selecionar "características desejáveis" para embriões, com o que, não apenas são evitadas possíveis doenças de fundo genético, mas é projetado um ideal de humanidade perfeita, ou mais perfeita do que aquela

\footnotetext{
${ }^{2}$ A este respeito, conferir também: Escóssia (1999); Kastrup (2000).
} 
recebida pela nossa destinação natural enquanto membros de uma espécie determinada. ${ }^{3}$

Também na educação, o influxo da tecnologia tornou-se preponderante. A proliferação de materiais, livros, artigos, teses acadêmicas, insistem em afirmar, e existem razões mais do que plausíveis para tal insistência, que uma dimensão decisiva do significado da educação no século XXI apenas será configurada adequadamente quando forem incorporados os desafios lançados pela tecnologia. E o motivo para tal afirmação consiste em perceber, e neste particular o juízo está corretíssimo, que as novas tecnologias implicam um novo modo de conceber o próprio processo de constituição do conhecimento, além de expressar a necessária interação entre a escola e o mundo, afinal, incoerente seria conceber a escola como um espaço absolutamente autônomo, embora não seja necessário, sequer desejável, pensá-la como um espaço totalmente dependente.

Assim, o que há de fundamental e digno de destaque na insistência crescente pela incorporação da tecnologia à educação não se refere à mera incorporação de novos objetos à escola, em que, não sendo mais eficientes o giz, o quadro-negro e o por vezes monótono discurso do professor, agora ter-se-ia um novo objeto - o computador -, que substituiria os velhos objetos obsoletos. $\mathrm{O}$ computador torna-se preponderante na medida em que revela um outro modo de mediação com o mundo e conosco . Portanto, "computador na escola", "educação à distância" - temática que introduz outro tópico decisivo para uma sociedade como a nossa, a saber, o tópico da democratização do acesso ao conhecimento são noções a revelar mudanças decisivas, não apenas nas formas

\footnotetext{
${ }^{3}$ Uma das polêmicas filosóficas mais acirradas dos últimos 20 anos, travada por Habermas $e$ Sloterdijk - embora jamais tenha havido um debate de fato entre os autores, tratou-se de uma polêmica nos bastidores - deveu-se a um posicionamento antagônico entre os dois autores a respeito do significado da engenharia genética, bem como sobre a razoabilidade e legitimidade da imposição de limites à pesquisa genética. Encontramo-nos num estágio tal que, em um tempo relativamente próximo, ser-nos-á possível programar as características genéticas dos nossos filhos. Aquilo que antes, num plano não biológico, cabia exclusivamente à religião, à moral, à educação, poderá receber um "complemento tecnológico". Este fato tecnológico possui consequências de amplo alcance, não apenas éticas, jurídicas, mas também, ontológicas, educacionais. A este respeito, conferir: Sloterdijk (2000); Habermas (2010). Também a este respeito, afirma Kunzru (2009, p. 122): "Existe, agora, a possibilidade de se fabricar humanos melhores, ampliando suas capacidades por meio de dispositivos artificiais".
} 
institucionalizadas de manter e promover a educação, mas principalmente, nas formas mais extensivas de pensar a própria constituição do humano.

Contudo, embora tais ideias revelem uma dimensão importante do problema, elas podem, ainda assim, deixar escapar um dos aspectos mais decisivos para apreender a real extensão do que está implicado na tecnologia, a saber, o problema da sua definição e da sua consequente significação. O mero uso de objetos tecnológicos, tanto no quotidiano, quanto na escola, ainda não significa que tenhamos a real extensão do que seja a tecnologia. A este respeito, Gilbert Simondon (2007, p. 267) afirma: "[...] possuir uma máquina não é conhecê-la"; e o mero uso de objetos tecnológicos na escola também não implica que já esteja resolvido o problema do alcance da percepção e da intelecção do que é um objeto tecnológico, qual sua relação com o animal, com o humano e, enfim, com a natureza. E o modo como, via de regra, é concebido o computador na escola, a saber, como um objeto usado para resolver um problema, ou um objeto que, ao agenciar processos de cognição, auxilia, facilita o processo de conhecimento, revela que talvez ainda não saibamos posicionar adequadamente os objetos tecnológicos no plano das realizações humanas.

Com essa ressalva não se pretende introduzir uma correção ao modo como na educação, é pensado o tema da tecnologia. Não se trata, portanto, nem de apresentar uma crítica à incorporação da tecnologia à educação, muito menos de mostrar uma insuficiência dos discursos que elegem a tecnologia como um fato para pensar a educação. Pretende-se operar por extensão, não por limitação. Busca-se tão só indicar a necessidade premente de refletir sobre a realidade dos objetos tecnológicos; sobre a necessidade de definir claramente o que é um objeto tecnológico, antes de usá-lo como um dado evidente, mostrando com isso suas conexões com as realidades humanas e naturais. Por conseguinte, busca-se apontar para a necessidade da constituição de uma ontologia crítica do objeto tecnológico, pois o mero uso de objetos tecnológicos, sem tal reflexão e definição, pode levar a constituição de uma ignorância profunda: a não percepção do que seja aquilo com o qual lidamos e que nos constitui à medida em que somos formados, seja na escola ou nos planos mais amplos de nossa vida. 
Tendo em vista as motivações acima indicadas, o objetivo deste artigo é apresentar o modo como Gilbert Simondon, em sua obra O Modo de existência dos objetos técnicos, concebe o objeto técnico e mostrar suas possíveis relações com o tema do ensino da técnica. Para tanto, divide-se em dois momentos: o primeiro, em que serão apresentados os principias argumentos de Simondon para defender a tecnologia e os objetos técnicos frente a acusação de restrição da experiência humana e de destruição da cultura; o segundo, em que será refeita a genealogia do objeto técnico proposta pelo autor, para então, abordar o tema do ensino refletido da técnica, procedimento decisivo para apreender a análise do significado extensivo do objeto técnico enquanto uma realidade humana e a necessidade do ensino da técnica. Tal conjunção viabilizaria, ao juízo de Simondon, uma verdadeira reforma da cultura na medida em que apreenderia o objeto técnico enquanto mediador entre o homem e a natureza, vinculando cultura, natureza e objeto técnico.

\section{Objeto técnico enquanto mediação entre homem e natureza}

Hans-Georg Gadamer, no encerramento de uma de suas últimas conferências, intitulada "Educação é educar-se", em 19 de maio de 1999, no Dietrich-Bonhoeffer-Gymnasium da cidade de Eppelheim, proferiu uma sentença marcante sobre o futuro da educação num mundo cada vez mais dominado pela tecnologia: "Mantenho-me na posição de que, se o que alguém quer é educar-se e formar-se, é de forças humanas que se trata, e que somente assim sobreviveremos incólumes à tecnologia e ao ser da máquina" (Gadamer, 2000, p. 48). Longe de ser a expressão desencantada de um filósofo no alto dos seus 99 anos, pois Gadamer jamais se mostrou pessimista, a frase revela, contudo, uma das características marcantes da reflexão filosófica do século XX sobre a tecnologia ao menos em autores de língua alemã -, a saber, a suspeita de que há um perigo inscrito em sua essência e que, se a tecnologia não for dimensionada adequadamente, ela ameaça destruir a humanidade. A este respeito, Arnold Gehlen, no parágrafo de abertura de sua obra A Alma na era da técnica, ao mostrar as motivações e os equívocos deste modo de conceber a técnica, apresenta 
um panorama elucidativo sobre o modo como habitualmente a técnica foi concebida na Alemanha. Diz Gehlen (s. d., p. 15):

É raro que a abundante literatura crítica, que floresce na Alemanha desde Nietzsche e Spengler, não apresente uma tonalidade polémica contra a técnica. Temos de aceitar isto como sintoma de que a nossa sociedade ainda não terminou o íntimo debate com as profundas alterações que sofreu no processo de industrialização. Na vida pública têm larga expansão as receosas previsões de um futuro em que dominará o "estado de termitas", o alastramento das massas, a teledirecção do cérebro, da personalidade e a decadência da cultura.

Muitos foram os autores que corroboraram este modo polêmico, negativo de pensar a técnica. Dentre eles, apenas para citar alguns de uma longa lista possível, destaco: Hannah Arendt (2010, p. 21-25); Christoph Türcke (2010, p. 0912; p. 173-232); Martin Heidegger (2002a; 2002b); Walter Benjamin (1996, p. 166); Günther Anders (1987); Theodor Adorno \& Max Horkheimer (1985, p. 15) e Hans Jonas (1985, p. 15; p. 302-305). Embora não haja unanimidade a respeito de todos os elementos deste intrincado problema, ainda assim é possível identificar um acordo quanto a dois aspectos: $1^{\circ}$. a tecnologia, enquanto produto da técnica, representa um perigo para a humanidade; $2^{\circ}$. a compreensão da tecnologia só se torna plena se fundamentada numa reflexão sobre a essência da técnica ${ }^{4}$.

Com a obra de Gilbert Simondon o panorama dos questionamentos sobre a técnica se altera significativamente. Apesar de conter uma reflexão de amplas consequências sobre o tema da técnica, dos objetos técnicos, e de expressar um juízo extremamente positivo dos objetos técnicos, e de ter sido uma referência importantíssima para filósofos do porte de Herbert Marcuse, Gilles Deleuze e Jean Baudrillard, somente a partir da década de 1990, tal importância transformou-se em influência, como nota Pablo Rodríguez, no prólogo à tradução espanhola da obra Du mode d'existence des objets techniques. Além da discrição pessoal e

\footnotetext{
${ }^{4}$ Neste particular, a obra de Heidegger se destaca, justamente por ser a reflexão mais radical e de mais longo alcance a respeito de tais temas, razão pela qual serve de baliza para a caracterização desta posição de suspeita sobre a tecnologia e a técnica. A este respeito, conferir: Heidegger (2002a, 2002b).
} 
profissional, "[...] Simondon não aparece em nenhuma foto, não assina nenhum manifesto ou abaixo-assinado, não participa de nenhuma polêmica, não publica; suas duas teses, convertidas em livro, são o testemunho mudo de uma vida discreta" (Rodríguez, 2007, p. 10), ${ }^{5}$ também contribuiu para a tardia influência de sua obra sobre os objetos técnicos a dificuldade da linguagem e dos conhecimentos técnicos específicos em mecanologia (Hart, 1989, p. VII) exigidos para a sua compreensão.

O propósito da obra de Simondon é chamar a atenção para o sentido dos objetos técnicos. Por essa razão, não lhe interessa, como em Heidegger, pensar a técnica como desencobrimento, donde emerge um juízo extremamente crítico à técnica ${ }^{6}$, e sim, mostrar que ao recusar o objeto técnico, a cultura recusa uma dimensão decisiva da própria realidade humana, na medida em que os objetos técnicos revelam uma realidade humana, e que tal recusa expressa uma parcialidade da própria cultura. Por isso,

\begin{abstract}
Simondon, poucos anos após a conferência de Heidegger, inicia seu livro com uma declaração de princípios, ou uma declaração de guerra: este clima intelectual criou um preconceito inútil a respeito da técnica que nos impede de ver o seu lugar na existência humana. A cultura gerou um ressentimento em relação à técnica, graças a um "humanismo fácil", que desconhece a realidade humana nos objetos e sistemas técnicos e, muito especialmente, nas máquinas (Rodríguez, 2007, p. 15).
\end{abstract}

Quer dizer, a própria expressão plena da cultura não se efetiva sem a incorporação positiva dos objetos técnicos no plano da sua representação. Longe se encontra o sistema de defesa que a cultura ou o pensamento filosófico armavam

\footnotetext{
${ }^{5}$ No ano de 1958, na Sorbonne, para receber o título de Doutorado de Estado (Doctorat d'Etat), Simondon defendeu a tese principal intitulada L'individuation a la lumière des notions de forme et d'information, seguida da tese secundária, intitulada Du mode d'existence des objets techniques. Uma parte da tese principal foi publicada, em 1964, pela Presses Universitaires de France, enquanto a tese secundária foi publicada, uma primeira vez, pela Éditions Montaigne e, posteriormente em 1989, pela Éditions Aubier. A tese principal somente foi publicada na íntegra em 2005, pela Éditions Jérôme Millon. Outras obras, em grande parte resultados de cursos, passaram a ser publicadas a partir de 2000. Ou seja, não é exato, como afirma Rodríguez, que Simondon não tenha publicado. Publicou pouco, se comparado aos outros filósofos de sua geração.

${ }^{6}$ A respeito da concepção heideggeriana da técnica, conferir: HEIDEGGER, 2002a; WEBER, 2011.
} 
contra técnica. Não há, portanto, oposição entre cultura (humanidade) e técnica (desumanizadora), e sim, complementariedade. Diz Simondon (2007, p. 09):

A oposição sustentada entre a cultura e a técnica, entre o homem e máquina, é falsa e sem fundamento; ela esconde ignorância e ressentimento. Por trás de um humanismo fácil, ela mascara uma realidade rica em esforços humanos e em forças naturais, e que constitui o mundo dos objetos técnicos, mediadores entre a natureza e o homem.

Os objetos técnicos são mediadores tecnológicos entre a natureza e o homem. O que daí resulta? A explosão da identidade e a instauração da diferença. Em primeiro lugar, não há dualidade na relação homem/natureza, pois os objetos técnicos funcionam como mediadores, mostrando a impossibilidade de se compreender homem e natureza sem a mediação. Ou seja, eles não podem ser compreendidos como algo em si. Além disso, as mediações tecnológicas também não se confundem com os pólos da mediação; em segundo lugar, mesmo a relação homem/objeto tecnológico não é dual, haja vista a natureza mediadora do objeto tecnológico, o que também impede de se conceber a relação homem/objeto tecnológico como uma mera relação sujeito/objeto, pois, o objeto tecnológico possui uma peculiaridade que o distingue dos objetos naturais: ele é mediador entre o homem e a natureza.

A recusa da oposição entre os objetos técnicos e a cultura atinge o ponto extremo, e aqui se institui uma relação direta com a educação, quando Simondon afirma que é possível voltar a dar à cultura seu caráter verdadeiramente geral, por meio da reintrodução, na cultura, de uma consciência da natureza das máquinas, das relações que elas possuem entre si e com o homem, bem como dos valores implicados na relação entre homem e máquina. Ou seja, se a cultura perdeu seu caráter geral, é no âmbito da tecnologia, dos objetos técnicos - posto que a tecnologia impõe gradativa $e$ intensivamente sua presença em todos os domínios da nossa vida -, que ela poderá voltar a adquirir a generalidade. Complementando esta ideia, ele afirma: 
Além disso, os esquemas fundamentais de causalidade e de regulação, que constituem uma axiomática da tecnologia, deverão ser ensinados de um modo universal, como são ensinados os fundamentos da cultura literária. A iniciação às técnicas deve ter lugar no mesmo plano que a educação científica [...] Uma criança deverá saber o que é uma autoregulação ou uma reação positiva do mesmo modo como ela conhece os teoremas matemáticos (Simondon, 2007, p. 13-14).

A reintrodução do objeto técnico na cultura seria efetivada por uma educação para a técnica, o que levaria, de acordo com ele, a uma "reforma da cultura, em que se procederia por alargamento e não por destruição" (Simondon, 2007, p. 14).

Como já apontado na última nota, Du mode d'existence des objets techniques, obra referencial para as observações feitas acima, foi a tese secundária à tese principal intitulada L'individuation a la lumière des notions de forme et d'information. Tal conjunção poderia levar à indagação: que relação existe entre o problema da individuação e o tema da técnica e da tecnologia, que teria levado Simondon a complementar seu estudo sobre a individuação com o estudo dos objetos técnicos? E mais, qual relação há entre individuação e ensino refletido da técnica?

O tema aglutinador das duas teses é a ideia de mediação e a negação da unidade, tanto no que se refere à individuação quanto no que diz respeito à técnica $e$ à relação entre os objetos técnicos e a cultura. Na obra sobre a individuação a recusa da unidade e a instauração da diferença adquirem estatuto pleno na recusa, tanto do substancialismo quanto do hilemorfismo, que concebem a existência de "um princípio de individuação anterior à individuação, suscetível de explicá-la, produzi-la, conduzi-la" (Simondon, 2009, p. 23). Tal recusa levará o autor a extrair uma consequência de amplo alcance, inclusive metodologicamente, por meio do posicionamento exato da compreensão da individuação:

Gostaríamos de mostrar que é preciso operar uma inversão na busca do princípio de individuação, considerando como primordial a operação de individuação a partir da qual o indivíduo chega a existir e cujo desenvolvimento, regime $e$ modalidades ele reflete em seus caracteres. O indivíduo será 
captado, então, como uma realidade relativa, uma certa fase do ser que supõe, antes dela, uma realidade pré-individual e que, ainda após a individuação, não existe completamente sozinha, pois a individuação não consome, de um golpe, os potencias da realidade pré-individual $e$, por outra parte, o que a individuação faz aparecer não é somente o indivíduo, senão a dupla indivíduo-meio. Assim, o indivíduo é relativo em dois sentidos: porque não é todo o Ser e porque resulta de um estado do Ser no qual não existia como indivíduo nem como princípio de individuação (Simondon, 2009, p. 26).

Esta caracterização levará Deleuze a afirmar: "E o que Simondon elabora é toda uma ontologia, segundo a qual o Ser nunca é Uno" (Deleuze, 2006, p. 121). E o conceito em que a recusa da unidade, no âmbito da discussão sobre a individuação, mostra-se em toda sua extensão é o de transdução. Tal conceito expressa a operação da negação da unidade e de instituição da diferença e da relação. Diz Simondon (2009, p. 380):

Entendemos por transdução uma operação física, biológica,
mental, social pela qual uma atividade se propaga
progressivamente no interior de um domínio, fundando esta
propagação sobre uma estruturação do domínio operada
aqui e ali: cada região de estrutura constituída serve de
princípio de constituição à região seguinte, de modo que
uma modificação se estende assim progressivamente, ao
mesmo tempo que a própria operação estruturante.

Se isso pode ser dito da individuação, com a mesma razão poderá ser dito da relação homem-objeto técnico, pois tanto um quanto outro não existem independentemente da relação, a ponto de se poder afirmar que é a própria relação que os constitui. Se há, como quer Deleuze, uma ontologia que nega a unidade na obra sobre a individuação, o mesmo pode ser dito, pelas mesmas razões, acerca da tese secundária sobre os objetos técnicos, daí sua coerência temática e argumentativa. Assim sendo, o ensino refletido da técnica operaria uma verdadeira reforma da cultura ao mostrar, por um ato de inteligência, que não há oposição entre os objetos técnicos e o homem, pois eles próprios não são em si, pois ambos resultam de um processo de mediação, de transdução, do qual a 
unidade está ausente "desde o princípio". Transdução é o conceito cunhado pelo autor que sintetiza, tanto o sentido relacional de homem, natureza e objeto técnico, quanto do processo no qual cada qual se torna indivíduo. Nas palavras esclarecedoras do próprio autor: "Não há princípio de individuação, somente processo" (Simondon, 2009, p. 123).

\section{Genealogia do objeto técnico e "ensino refletido da técnica"}

A que se deve a recusa à técnica e á tecnologia? A resposta a esta pergunta é decisiva, pois nas razões que justificam a recusa serão encontradas, ora implicitamente ora explicitamente, certas compreensões do objeto técnico, sempre negativas, que esclarecem a própria recusa. Por esse motivo, é imperativo perceber que não se trata simplesmente de opor um ajuizamento positivo a uma recusa da incorporação do objeto técnica à cultura, e sim, apreender a tecnicidade como parte de um sistema, jamais considerando-a como uma realidade isolada (Simondon, 2007, p. 174). Quer dizer, não seria correto, sequer produtivo, operar uma defesa da técnica sem fazer uma genealogia da tecnicidade, dos objetos técnicos, sem mostrar sua gênese (Simondon, 2007, p. 41), sem mostrar sua relação com as outras realizações humanas, pois, do contrário, apenas instalar-se-ia uma nova compreensão equivocada, a saber, a da superioridade e perfeição dos objetos técnicos sobre o humano.

Arnold Gehlen, um dos raros teóricos alemães que na primeira metade do século XX pensou positivamente a técnica, esclarece um primeiro conjunto de razões para a recusa à técnica e à tecnologia:

Os motivos desta resistência a uma $<<$ equiparação $>>$ valorativa da técnica aos outros domínios da cultura são obscuros [...] Talvez que as velhas concepções burguesas da supremacia das ciências contemplativas sobre a prática, das ciências puras sobre as aplicadas, desempenham o seu papel neste estado de coisas. Ou talvez se mantenha ainda a velha tradição, segundo a qual todos os problemas humanos se podem tratar com os instrumentos conceptuais da filosofia idealista, e os meios de que esta dispõe não se sentem competentes perante a técnica. Quase não se pode contestar que a generalidade dos nossos conceitos filosóficos está 
muito aquém das exigências dos dados do presente (Gehlen, s.d., p. 15).

O tom relativamente inseguro na resposta - o autor inicia as frases que indicam as causas com "talvez" - não deixa, contudo, de indicar o lugar preciso do problema: a utilização de referenciais equivocados para pensar a relação da técnica com outros domínios da cultura: supremacia das ciências contemplativas sobre as ciências práticas; utilização dos referenciais da filosofia idealista. A conclusão aponta para um aspecto digno de interesse: tanto num caso como no outro, tais referenciais são incompetentes para dar conta do que está em jogo na técnica, pois o presente introduz - "talvez" hoje de um modo muito mais crônico do que na época em que Gehlen publicou seu livro - desafios que os velhos conceitos filosóficos gastos não mais abarcam em seus esforços explicativos.

O próprio Simondon (2007, p. 271) endossa esta interpretação na medida em que, no parágrafo de conclusão de sua obra, afirma:

Neste sentido, pode-se pensar que o dualismo inerente ao pensamento filosófico, dualismo de princípios e de atitudes motivado pela dupla referência ao teórico e ao prático, será profundamente modificado pela introdução da atividade técnica considerada como terreno de reflexão no pensamento filosófico.

E arremata: "Parece que esta oposição entre a ação e a contemplação, entre o móvel e o imóvel, deve terminar frente a introdução da operação técnica no pensamento filosófico como terreno de reflexão e, inclusive, como paradigma" (Simondon, 2007, p. 271). O autor sugere explicitamente que uma consideração coerente sobre a especificidade da técnica mostrará a insuficiência, e mesmo os equívocos, das operações teóricas e práticas que insistem em não reconhecer as conexões essenciais entre técnica e cultura. Esta transformação necessária, que não significa apenas uma transformação de "pontos de vista", possui um "[...] alcance epistemológico" (Simondon, 2007, p. 270). ${ }^{7}$

\footnotetext{
${ }^{7}$ Trinta anos após a publicação da obra de Simondon sobre os objetos técnicos, Pierre Lévy retoma esta ideia ao dizer que "Não se pode mais conceber a pesquisa científica sem uma aparelhagem 
Sumamente interessante é perceber que o abandono da oposição entre o teórico e o prático, o abandono do juízo valorativo segundo o qual a contemplação seria superior à ação, porém, deve ser efetivado, não apenas pelos críticos da tecnologia, mas, paradoxalmente, também pelos seus defensores, pois, defender a técnica $e$ a tecnologia ainda não significa necessariamente que se tenha compreendido o que elas sejam. Aliás, Simondon mostrará em sua obra que na própria atitude inerente à defesa entusiasta da tecnologia, muito em voga nas décadas de 1940 e 1950 em virtude dos avanços da cibernética, também se encontra um equívoco, uma incompreensão, tanto quanto na recusa da tecnologia ou na sua inferiorização frente à cultura. A este respeito, na introdução, Simondon (2007, p. 32) afirma:

O homem que quer dominar seus semelhantes suscita a máquina andróide. Abdica, então, frente a ela, e delega-lhe sua própria humanidade. Busca construir a máquina de pensar, sonhando em poder construir a máquina de querer, a máquina de viver, para permanecer por trás dela sem angústias, livre de todo perigo, isento de todo sentimento de debilidade e triunfante, de modo imediato, por aquilo que inventou. Pois bem: neste caso, a máquina convertida pela imaginação neste duplo do homem que é o robô, desprovido de interioridade, representa de modo demasiado evidente e inevitável, um ser puramente mítico e imaginário.

Ou seja, se há um equívoco crônico no juízo que opõe técnica e cultura, também se equivocam aqueles que concebem o objeto técnico como a realização suprema da humanidade, a partir do qual apreender-se-ia a perfeição realizada da natureza humana, como se o objeto técnico realizasse com perfeição as potencialidades, ou mesmo a essência, da humanidade. Por essa razão, a genealogia do objeto técnico, por meio da qual se dará a introdução adequada do objeto técnico no âmbito da cultura, operará uma reforma profunda: não apenas obrigará a desfazer os juízos negativos sobre o objeto técnico, mas também, obrigará a uma reformulação dos juízos supostamente positivos, porque também

complexa que redistribui as antigas divisões entre experiência e teoria. Emerge, neste final do século $\mathrm{XX}$, um conhecimento por simulação que os epistemologistas ainda não inventariaram" (Lévy, 2010, p. 07). 
equivocados, pois, do contrário, apenas inverter-se-iam os pólos e, com isso, instaurar-se-ia uma nova incompreensão, qual seja, a da superioridade unidimensional do prático sobre o teórico, das máquinas sobre o humano. Simondon recusa, portanto, tanto a tecnofobia quanto a tecnolatria. ${ }^{8}$

Embora estas causas sejam relevantes para a compreensão de uma dimensão importante da recusa da técnica enquanto realidade significativa do humano, todavia elas ainda não mostram o motivo mais decisivo para a instauração deste equívoco milenar. A causa fundamental, ao juízo de Simondon, reside na equiparação do objeto técnico com o instrumento, motivada pela sua submissão ao trabalho.

O objeto técnico foi apreendido através do trabalho humano, pensado e julgado como instrumento, co-adjuvante ou produto do trabalho. Pois bem, seria necessário poder operar, a favor do próprio homem, uma inversão que permitisse, ao que há de humano no objeto técnico, aparecer diretamente sem passar pela relação do trabalho. É o trabalho que deve ser conhecido como fase da tecnicidade e não a tecnicidade como fase do trabalho, porque a tecnicidade é o conjunto do qual o trabalho é uma parte, e não o inverso. (Simondon, 2007, p. 257).

O primeiro passo da genealogia da técnica será, então, explicitar as razões para a constituição de um equívoco milenar que consistiu em apreender o objeto técnico como instrumento, como máquina, como alguma coisa com a qual, mediante a forma trabalho, realizava-se alguma outra coisa. Ou seja, um objeto que, associado ao trabalho, permitia criar outros objetos. Tal modo de conceber o objeto técnico, embora habitual, equivoca-se no mais fundamental, pois, ao concebê-lo como máquina (Simondon, 2007, p. 162), como uma realidade fechada, uma unidade absoluta, um bloco fechado, encobre-se com isso sua especificidade, a saber, o seu funcionamento. Um objeto técnico define-se pelo seu funcionamento! Por essa razão, diz Simondon (2007, p. 260): "Não se pode falar do trabalho de uma máquina, mas apenas do seu funcionamento, que é um

\footnotetext{
${ }^{8}$ A respeito do significado destes termos, conferir: Silva (1999).
} 
conjunto ordenado de operações". E uma consideração adequada do objeto técnico a partir do princípio ou do paradigma do funcionamento mostraria que sua especificidade reside em seu funcionamento, não em seu caráter utilitário (Simondon, 2007, p. 262). Contudo, tal dimensão da realidade dos objetos técnicos só pode ser apreendida quando for explicitado o significado da idéia, central em Simondon, segundo a qual o objeto técnico é uma mediação entre o homem e a natureza. O que é a mediação, entendida neste sentido? Qual é a condição para que haja, nesse sentido, mediação?

A resposta a tais indagações conduz ao segundo passo da genealogia da técnica, que consiste em apreender os três níveis do objeto técnico, quais sejam: o elemento técnico, o indivíduo técnico e o conjunto técnico (Simondon, 2007, p. 37). Toda a primeira parte da obra é dedicada a apresentar tal gênese e a conclusão que cabe reter é que o objeto técnico jamais é um elemento fechado em si mesmo, pois, dada sua constituição, ele se relaciona com outra realidade técnicas, bem como com realidades humanas. Conceber desse modo os objetos técnicos, o computador, por exemplo, implica em reconhecer a mediação como sua característica distintiva.

Após apreender os elementos gerais mais importantes, foram criadas as condições para abordar o problema fundamental, assim formulado por Simondon (2007, p. 171):

A existência dos objetos técnicos e as condições de suas gênese põem, ao pensamento filosófico, uma questão que ele não pode responder por meio da simples consideração dos objetos técnicos em si mesmo: qual é o sentido da gênese dos objetos técnicos em relação com o conjunto do pensamento, da existência do homem e de sua maneira de ser no mundo?

Desde o início a própria gênese do objeto técnico põe o problema em termos relacionais, de mediação: ao mesmo tempo em que tal gênese é do objeto técnico, ela permite, ou mais exatamente, obriga, a falar da existência do homem e do próprio mundo. Isso mostra que a técnica representa uma fase, cuja outra fase é a religião, da evolução da relação homem-mundo, cujo modo principal é o modo 
mágico de ser no mundo, considerado como central e original. Assim, teríamos o seguinte quadro ilustrativo de tais relações:

\begin{tabular}{|c|c|c|}
\hline \multicolumn{3}{|c|}{$\begin{array}{l}\text { RELAÇÃO HOMEM MUNDO } \\
\text { Modo mágico de Ser no Mundo } \\
\text { (Central e Original) }\end{array}$} \\
\hline $\begin{array}{l}\text { (FASE) TÉCNICA } \\
\text { Teórico } \\
\text {. Prático }\end{array}$ & & $\begin{array}{l}\text { (FASE) RELIGIÃO } \\
\text {. Teórico } \\
\text {. Prático }\end{array}$ \\
\hline & $\begin{array}{ll}\text { ESTÉTICA } & \text { (Ponto } \\
\text { Neutro) } & \\
\text { Ciência (Teórico) } & \\
\text { Ética (Prático) } & \end{array}$ & \\
\hline
\end{tabular}

De amplas consequências, este modo de conceber a técnica posiciona o seu significado no domínio da mediação: o que Simondon mostra, e que já enunciamos em várias passagens do texto, é que a técnica não pode ser apreendida em si e por si mesma. Ela representa uma fase, um modo de responder à questão sobre o sentido do homem ser no mundo, pois,

Se este modo de existência está definido porque provém de uma gênese, esta gênese que engendra os objetos talvez não seja somente gênese de objetos ou, inclusive, gênese da realidade técnica: talvez ela venha de mais longe, talvez constitua um aspecto restrito de algo mais amplo, e talvez continue engendrando outras realidades após ter feito aparecer os objetos técnicos (Simondon, 2007, p. 171).

Trata-se do processo de individuação, do qual os objetos técnicos constituem uma dimensão do seu efetivar, e que ele próprio é concebível apenas enquanto processo. Não há princípio de individuação, somente processo. Por essa razão, o que daí resulta é sempre processual, mediado, tanto no domínio interno à tecnologia - em que ocorre a mediação entre elementos técnicos e relações interindividuais no conjunto técnico - quanto externo - aquele da relação dos objetos técnicos com o restante das "realidades humanas", da relação entre objeto técnico e cultura. 
Parece-nos, então, que se forem razoáveis as reflexões feitas até aqui, o tema do ensino refletido da técnica, por meio do qual seria possível superar a oposição entre tecnologia e cultura, impõe-se como uma necessidade para as reflexões de Simondon. E a conjunção entre técnica e cultura institui outra, também decisiva, a da filosofia da técnica com a filosofia da educação. A instauração da atitude tecnológica na cultura partiria do reconhecimento dos níveis ou momentos tecnológicos fundamentais da humanidade - Renascimento, Enciclopédia, Cibernética e Teoria da Informação (Simondon, 2007, p. 114-125) , mas ela se tornaria plena somente quando se efetivasse um ensino do que foi apreendido com a genealogia da técnica. Tal princípio metodológico presidiria o ensino refletido da técnica. Como isso se daria?

A introdução ao tema do ensino refletido da técnica se dá por meio do reconhecimento de que há dois modos fundamentais da relação do homem com o fato técnico, a saber: o da menoridade "[...] segundo o qual o objeto técnico é, antes de mais anda, objeto de uso" (Simondon, 2007, p. 105), característico do modo do homem se relacionar com o objeto técnico na infância, e que perdura no artesanato; o da maioridade, correspondente a uma tomada de consciência e uma operação reflexiva livre, "[...] que tem a sua disposição os meios de conhecimento racional elaborados pela ciência" (Simondon, 2007, p. 105). O artesão e o engenheiro, respectivamente os tipos mais característicos dos dois modos de considerar o objeto técnico, possuem um valor exemplar, pois "[...] através deles o objeto técnico se incorpora à cultura" (Simondon, 2007, p. 105). Contudo, de um modo insuficiente, pois até hoje ainda não lograram desfazer o equívoco que consiste em conceber o objeto técnico como inferior. Por essa razão, para que a cultura incorpore os objetos técnicos "[...] seria necessário descobrir um caminho intermediário entre o estatuto da maioria e o estatuto da minoria dos objetos técnicos" (Simondon, 2007, p. 107).

O primeiro passo para lograr com êxito a tarefa de incorporar o objeto técnico à cultura, seria considerar que o homem não é superior, nem inferior ao objeto técnico, mas que mantém com ele uma relação de igualdade, de reciprocidade de intercâmbios (Simondon, 2007, p. 108). 
O segundo passo seria o propriamente educativo, relacionado à formação técnica. Simondon (2007, p. 126) expressa toda a radicalidade de sua concepção ao dizer que:

\begin{abstract}
Existe uma cultura mais autêntica no gesto de uma criança que volta a inventar um dispositivo técnico que no texto em que Chateaubriand descreve esse "gênio espantoso" que foi Pascal. Estamos mais próximos da invenção quando tentamos descobrir o dispositivo para somar que utilizava engrenagens com aberturas, como a calculadora de Pascal (máquina aritmética), do que quando lemos as passagens mais eloquentes relativas à genialidade de Pascal.
\end{abstract}

O pressuposto do ensino refletido da técnica é a substituição da mera cultura vazia da palavra, pela instauração de uma cultura da criação técnica, em que se faz a experiência da invenção na exata medida em que se reconstitui o que presidia o elemento criativo original, mediado pela própria experiência criativa, não pela descrição em palavras. Nesta atitude distinta residem dois aspectos fundamentais: $1^{\circ}$. A crença, expressa em diretriz, de que mais vale para $\mathrm{o}$ aprendizado e a elaboração da inteligência, refazer um experimento ou construir uma máquina simples com as próprias mãos, do que apropriar-se de um complexo verbal referente a tal experimento, pois as palavras soarão vazias; $2^{\circ}$. A indicação de uma necessária revisão de nossa cultura livresca, de nossa cultura da palavra, pois

[...] a tecnologia exige um meio de expressão diferente da expressão oral, que utiliza conceitos já conhecidos e que pode transmitir emoções, mas que dificilmente pode expressar esquemas de movimento ou estruturas materiais precisas; o simbolismo adequado à operação técnica é o simbolismo visual, com seu rico jogo de formas $e$ proporções. A civilização da palavra deixa lugar à civilização da imagem (Simondon, 2007, p. 117).

O ensino refletido da técnica instauraria, então, uma nova suma civilizatória, na exata medida em que substituiria a civilização da palavra pela civilização da 
imagem. Ora, não nos encontramos já no âmbito da vigência da civilização da imagem? Ter-se-ia, então, logrado tal transformação civilizatória? De modo algum, pois nos encontramos sob o império da imagem sem, contudo, saber exatamente o que ela seja, pois não fomos educados para tal. A mera exposição às imagens, à tecnologia, no quotidiano ou na escola, não nos habilita automaticamente à compreensão do que elas sejam, Aqui, como em tudo, também temos que nos educar. Este parece ser, de acordo com Simondon, o grande desafio da educação nos tempos atuais: educar para o aprendizado do sentido dos objetos técnicos e da imagem. Isso seria desenvolver uma atitude tecnológica, que consistiria em que "[...] um homem não se preocupasse somente com o uso de um ser técnico" (Simondon, 2007, p. 162). Estaríamos a altura de sequer compreender tal exigência civilizatória?

\section{REFERÊNCIAS BIBLIOGRÁFICAS}

ADORNO, Theodor; HORKHEIMER, Max. Dialética do esclarecimento. Rio de Janeiro: Jorge Zahar, 1985.

ANDERS, G. Die Antiquiertheit des Menschen (2 vols). München: C.H. Beck, 1987.

ARENDT, Hannah. A condição humana. Rio de Janeiro; Forense Universitária, 2010.

BENJAMIN, Walter. "A obra de arte na era de sua reprodutibilidade técnica". In: Obras Escolhidas - Magia e técnica, arte e política. São Paulo: Brasiliense, 1996. p. 165-196.

DELEUZE, Gilles. "Gilbert Simondon, o indivíduo e sua gênese físico-biológica". In: A ilha deserta: e outros textos. São Paulo: Perspectiva, 2006. p. 117-121.

ESCÓSSIA, L. M. Relação homem-técnica e processo de individuação. Aracaju: Editora UFS, 1999.

FELINTO, Erick. A religião das máquinas. Ensaios sobre o imaginário da cibercultura. Porto Alegre: Sulina, 2005. 
GADAMER, Hans-Georg. Erziehung ist sich erziehen. Heidelberg: Kurpfälzischer Verlag, 2000.

GEHLEN, Arnold. A alma na era da técnica. Problemas de psicologia social na sociedade industrializada. Lisboa: Livros do Brasil, s.d.

HABERMAS, Jürgen. O futuro da natureza Humana. A caminho de uma eugenia liberal? São Paulo: WMF Martins Fontes, 2010.

HEIDEGGER, Martin. "A questão da técnica". In: Ensaios e conferências. Petrópolis, RJ: Vozes, 2002a. p. 11-38.

. "O tempo da imagem de mundo". In: Caminhos de Floresta. Lisboa: Fundação Calouste Gulbenkian, 2002b. p. 95-138.

JONAS, Hans. Technik. Medizin und Ethik. Praxis des Prinzip Verantwortung. Frankfurt: Suhrkamp, 1985.

KASTRUP. Virginia. "Novas tecnologias cognitivas: o obstáculo e a invenção". In: PELLANDA, N. M. C.; PELLANDA, E. C (Orgs). Ciberespaço: um hipertexto com Pierre Lévy. Porto Alegre: Artes e Ofícios, 2000. p. 38-59.

KUNZRU, Hari. "Genealogia do ciborgue". In: TADEU, Tomas (Org.). Antropologia do ciborgue. As vertigens do pós-humano. Belo Horizonte: Autêntica Editora, 2009. p. 119-126.

LÉVY, Pierre. As tecnologias da inteligência. O futuro do pensamento na era da informática. São Paulo: Editora 34, 2010.

Cibercultura. São Paulo: Editora 34, 2000.

RODRÍGUEZ, Pablo. "Prólogo. El modo de existencia de una filosofía nueva". In:

SIMONDON, Gilbert. El modo de existencia de los objectos tecnicos. Buenos Aires, Prometeo, 2007. p. 09-24.

SILVA, Bruno. "Questionar os fundamentos tecnológicos: tecnofobia versus tecnolatria”. In: I Conferência internacional Challenges'99/Desafios'99: Actas da I conferencia internacional de tecnologias de informação e comunicação. Braga: Universidade Minho, 1999. p. 73-88.

SIMONDON, Gilbert. Du mode d'existence des objets techniques. Paris: Aubier, 1989. 
El modo de existencia de los objectos tecnicos. Buenos Aires, Prometeo, 2007.

La individuacion. Buenos Aires: Editoral Catus / La Cebra Ediciones, 2009.

L'individuation a la lumière des notions de forme et d'information. Grenoble: Jérôme Millon, 2005.

SLOTERDIJK, Peter. Regras para o parque humano. Uma resposta à carta de Heidegger sobre o humanismo. São Paulo: Estação Liberdade, 2000.

TÜRCKE, Christoph. Sociedade excitada. Filosofia da sensação. Campinas, SP: Editora da UNICAMP, 2010.

WEBER, José Fernandes. "Técnica, tecnologia e cuidado (Sorge) em Heidegger". In: Revista da área de humanas. $N^{\circ}$. 61. Jul/Dez. 2011. p. 59-72. 